\title{
تاريخ الكوت وحصارها
}

الباهث مثنـى مهنز مهدي

واسبط/ العرأ

تسميمية الكوت

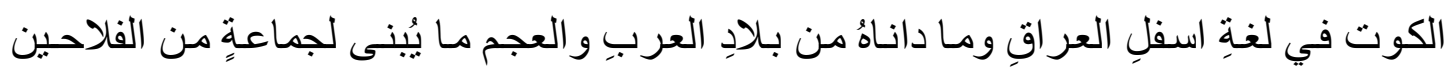

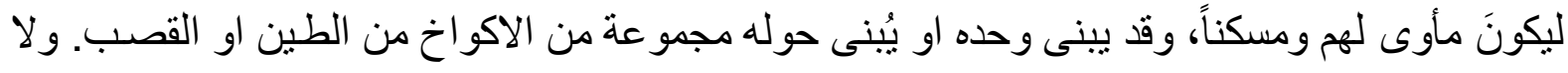

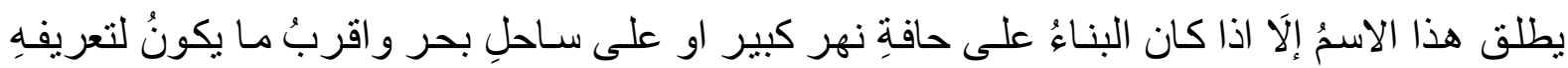

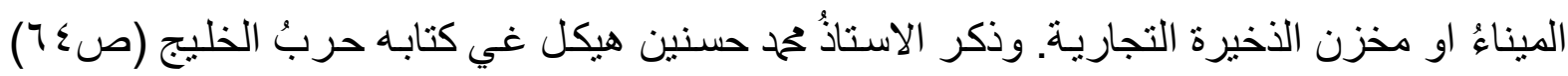

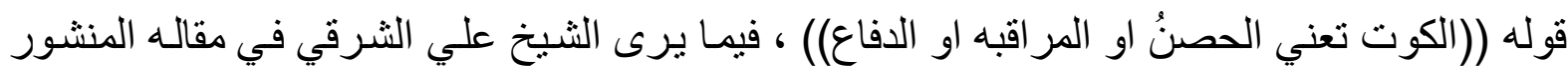

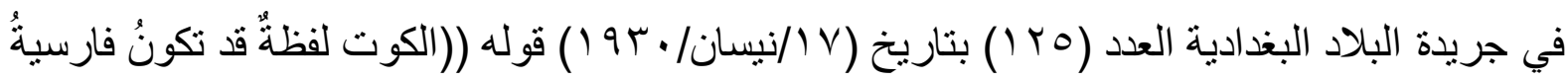

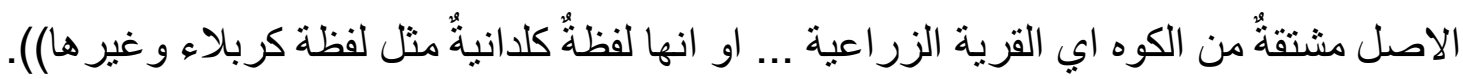

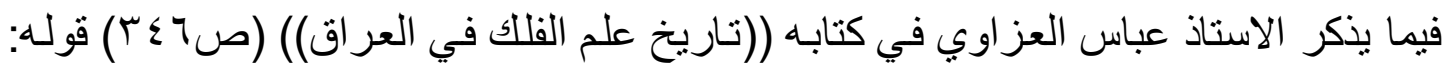

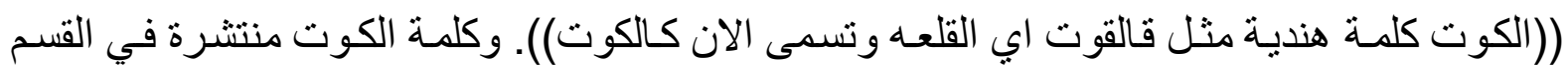

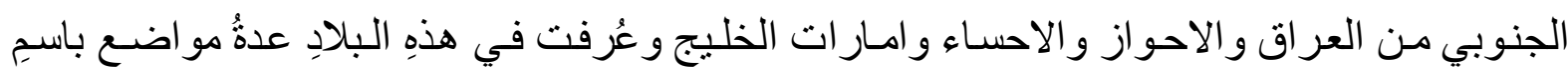
الكوت منها كوت الزين ... وكوت خليفة ... وكوت جار الله .. وكوت العصبيمي .. وكوت المعدر .. .

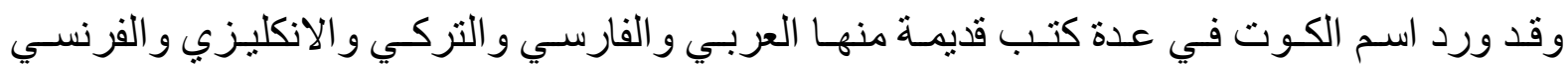
و الايطالي. لقد شاع اسم الكوت وذاع ولهع اسمها وتداولتها وكالات الانباء العالمية و اتجهت الابصـار

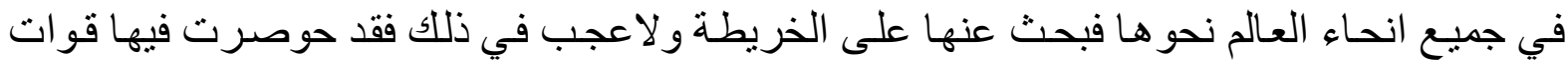

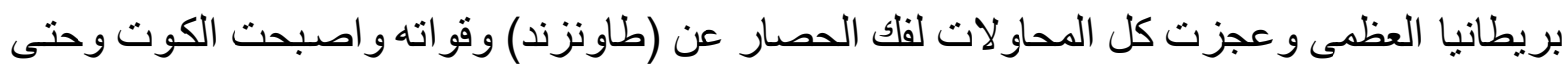
يومنا يدرس حصار ها في كافة الاكاديميات العسكرية في العالم لانه اطول حصار حدث في الحرب العالمية الاولى، حيث سلدت القوات البريطانية المحاصرة الى القوات التركية دون قيد او شرط.

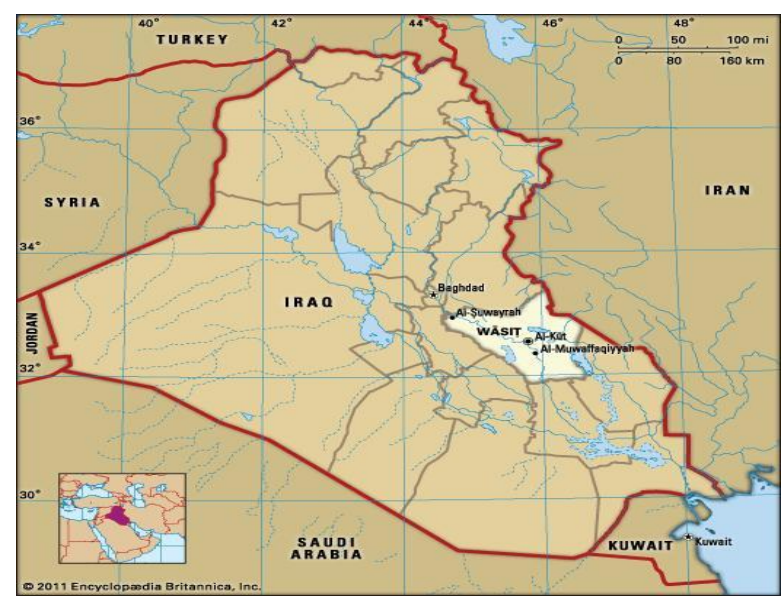

$-\varepsilon$ - 


\section{انشاء هدينة الكوت}

كان للضرورة حكم في انتساء مدينة الكوت حيث ان موقعها قريب من منتصف المسافة بين

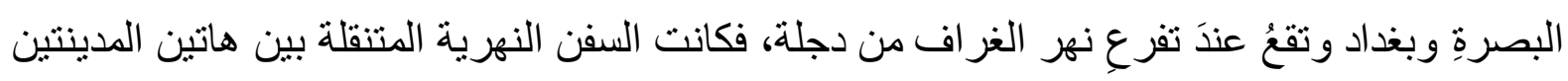
ترسو في الكوت لتفرغ حمولتها في سفن صغيرة تسبر في نهر الغر اف الى الحي والمدن التي تقع جنوبها وكان كثير من ركاب هذه السفن المتوجهين من البصرة الى بغداد يغادرون سفنهم عندما يصلون الكوت فياخذون عوضها الدواب لتوصلهم بطريق البر الى بغداد فيصلون في مدة ثلاثة ايام الى المدائن. ان الكوت انثأت اساساً كميناء نهري وحركة الملاحة قائمة منذ زمن بعيد اضـافة لحاجة الدولة العثمانية المحتلة لحركة قواتها. وقد ذكر المؤرخ الاستاذ (عبد الرزاق الحسني) قوله ((انشـأت الكوت عام r (1 (م بطلب من الحكومة العثمانية)) ثم جعلت منها مركز اً لادارة شؤون تلك المناطق لموقعها

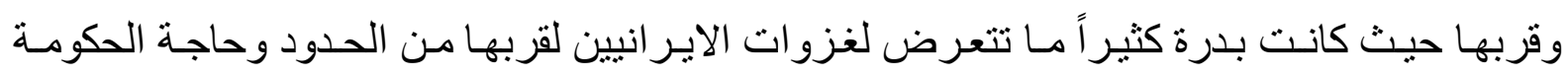
العثمانية لان تجعل من الكوت مركزاً قريباً من العثائر لملاحظة تحركاتهم فانشأت عندئذ مركزاً لادارة المنطقة ومرجعاً رسمياً قريباً من ولايتي بغداد والبصرة. وقد جاء في سالنامة الاستانة - و هي الجريدة

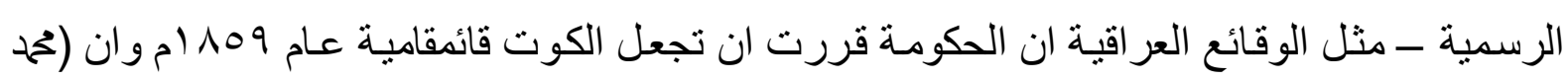
باثشا) كان محافظاً للو اء بدرة وجصان، حيث كانت الكوت قضاء تابعاً الى بدرة، حيث قام الو الي (تقي الدين باشا) بجو لات تققدية في انحاء قضاء الكوت ونوقف على احو ال عشائر ها. لقد كانت الكوت قرية ثم اصبحت من مواضع التجارة النهرية المهمة بعد ان حصلت شركة لنج

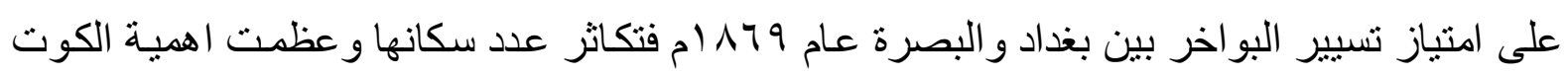
وصا لها ذكر في التجارة.

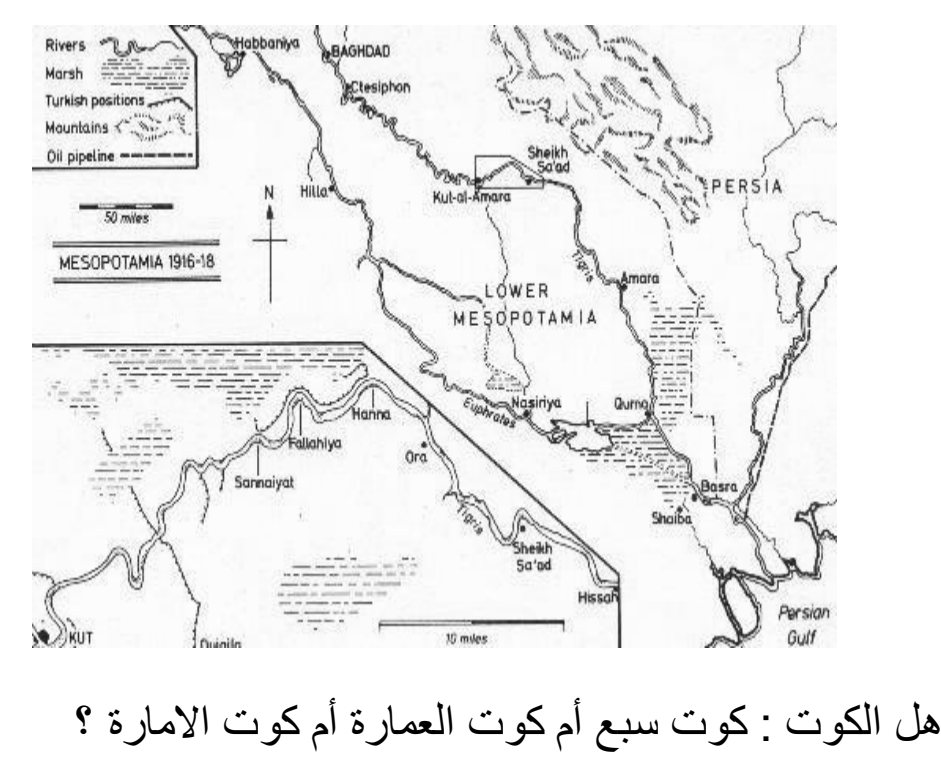




\section{كوت سبع}

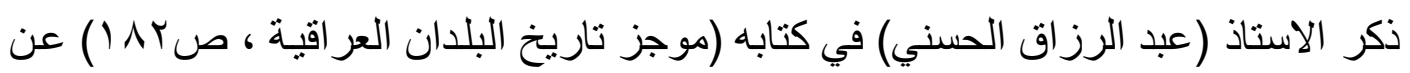
الكوت قوله (( قد بحثنا كثيرًا عن تاريخ انشاء هذه البلدة فروى لنا الطاعنون في السن ان اول من اقام البيوت فيها رجل من مياح بطن من ربيعة يدعى سبع بن خميس، رئيس تلك الاطر اف وذلك في عام ب ا 1 (م فنسبت اليهه ودعيت بكوت سبع)). اما رأي المحامي (جمال بابان) في كتابـه (اصول اسماء المدن) فيقول : ((ان اول رجل شيد قلعةً من الآجر في الكوت هو الثيخ سبع بي خميس. امـا الدكتور (عادل البكري) في كتابه (تاريخ الكوت، ص ا () فيذكر ((كانت عائلة سبع من اقدم العوائل

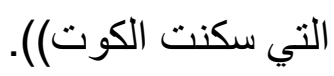

وكتب الرحاله الانكليزي (جيمس بوند) عام • بر ام اثناء زيارته للكوت : ((انتهزتُ دعوة الثيخ سبع فامضيت اياماً قليلة مع قبيلته وقد تمتعنا بالصيد و اعب الجريد)). وذكر الاستاذ (كاظم الدجيلي) في مجلة (المقتطف) قوله : كان سكان الكوت عشيرة بيت شاوي يسكنون في بيوت الثعر. وفي سنة جسم ام غزا علي رضـا لاز باثـا والي بغداد المحمرة ومر في طريقه على موقع الكوت وكان رئيس اهل الكوت بزون آل شـاوي فخصص الو الي جر ايات سنوية وهي كميـة من الحنطـة و الثعبر وان ياخذ مبالغ من المال عن كل سفينة تمر بالكوت.

\section{كوت العهارة :}

لان دجلة المنسلة من شمال هذا الموضع اي من النعمانية حتى القرنةِ كانت ولاتز ال تدعى شط العمارة. وذكر (فريزر) في كتابه (بين النهرين و آثنور) قوله : بعد ان يجري دجلة بين خر ائب طيسفون وسلوقيه يتدفق في ارضٍ غرينية و هنالك على طول النهر مضساربُ و اكو اخُ العربِ و عدة قرى كبيرة و اعظمها كوت العمارة. وذكر الرحالة (بريج) في كتابه المطبوع عام 1 | 1 ام (ويسمى الاعر اب نهر دجلة من الكوت الى القرنـة نهر العمـارة)). وقد تكون تسميته لتميزه عن غيره من الاكو ات وورد في

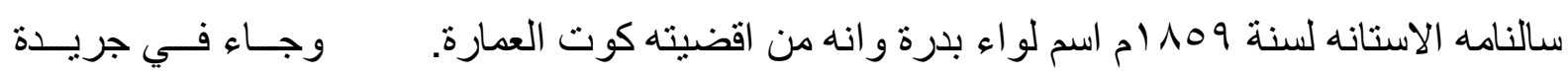

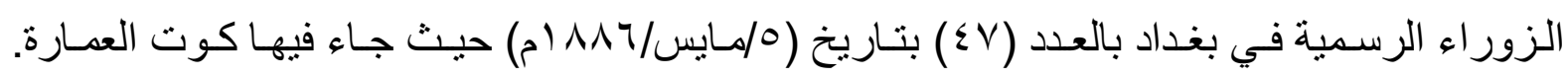
وفي كتاب السيد (عبد الرزاق الحسني) (قديماً وحديثاً ، صل ب ا I ) (و انما قيل لها كوت العمارة لوقوعها على هذا الثط - شط العمارة.

ان تسمية الكوت بكوت العمارة ليست لها ايبة علاقة بمدينـة العمارة الحالية لانها اسست حديثاً بعد الكوت بفترة طويلة، و امـا سبب تسمية دجلة بالعمارة فهو نسبة الى تسمية قديمة نرجع الى العهد العباسي نسبة الى (عمارة بن الوليد) عامل المنصور الذي اطلق اسمه على هذا الجزء من النهر كما يقول (د. عادل البكري) في كتابه (تاريخ الكوت). 


\section{كوت الاهمارة :}

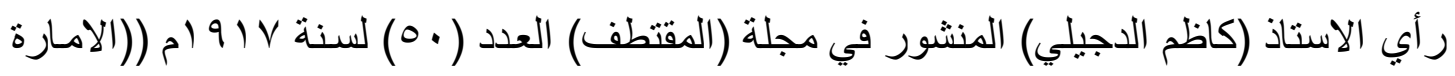

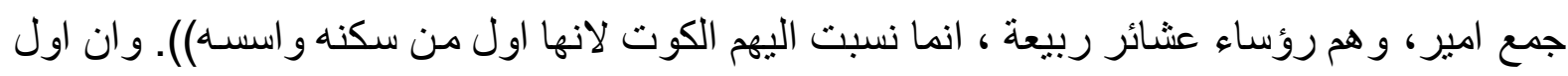

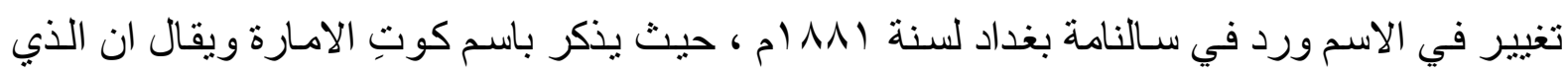

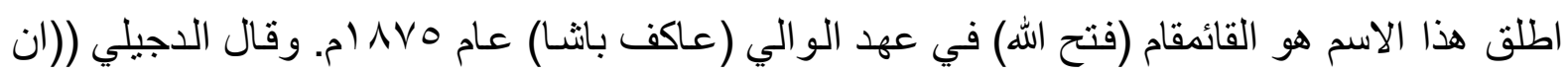

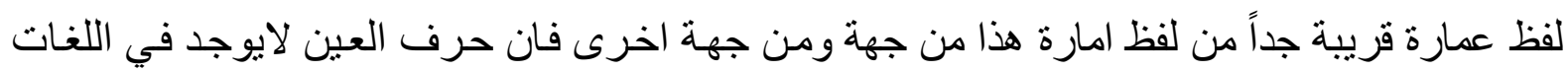

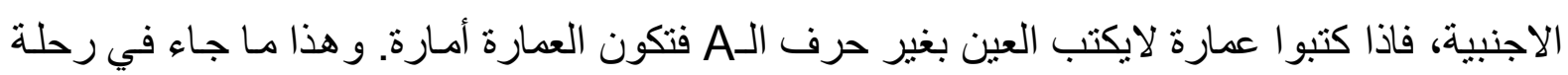

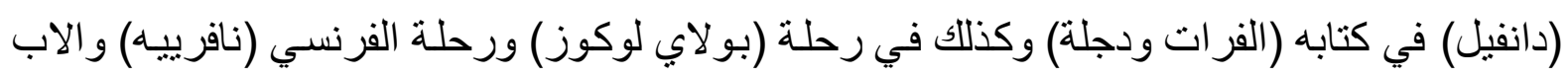

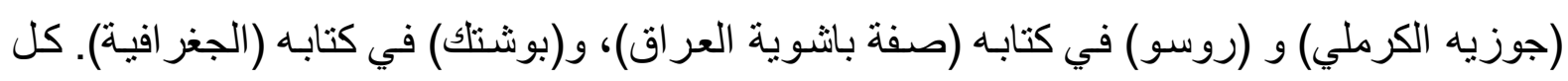
هؤ لاء صوروا لفظة العمارة بحرف الـA فتكون امارة ، و هناك سبب آخر لتسمية كوت العمارة بالامارة

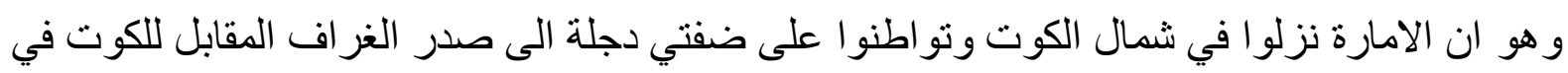
الجانب الثرقي و الغربي الى عدة كيلومترات.

\section{وصف هدينة الكوت :}

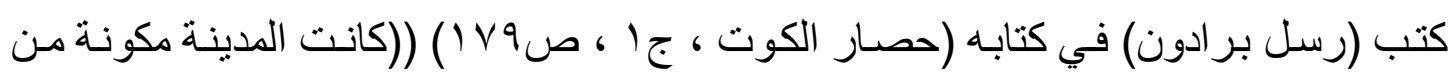

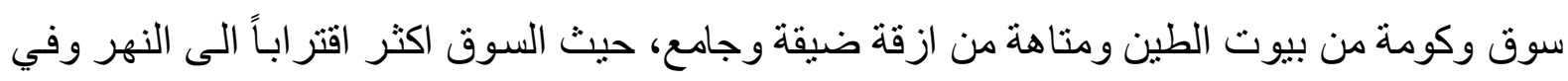

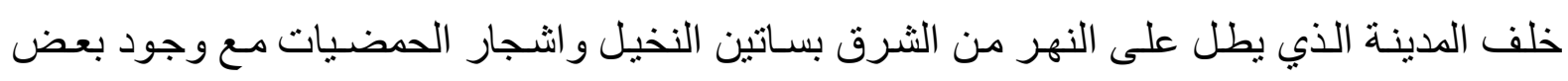

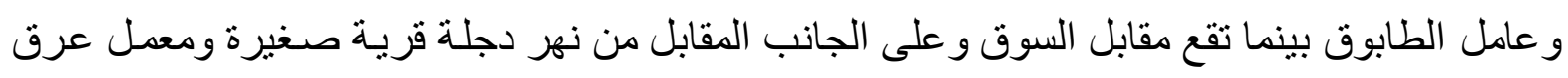

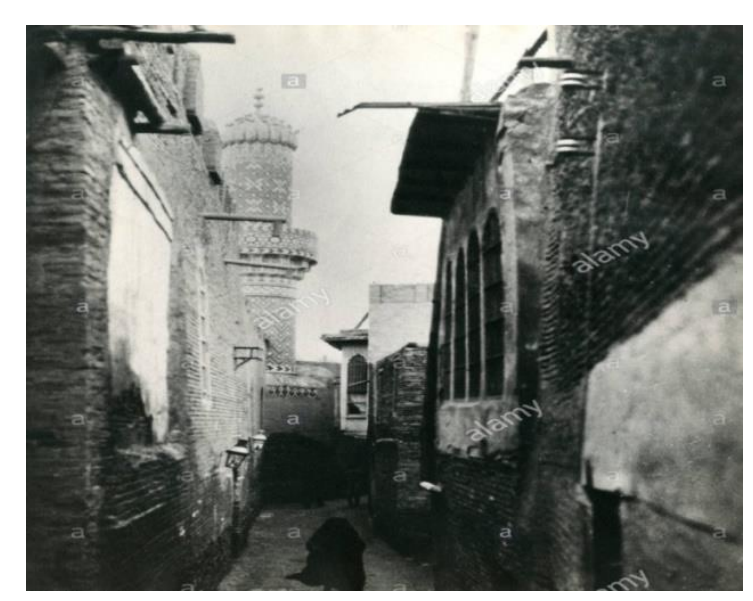

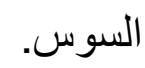

اما العالم الآثاري البريطاني والذي زار الكوت (ويلس برج) وهو من اثـهر الرحالة فقد تجول في الددينة وقال عنها ((انها بلدة صغيرة كثيرة المساجد وفيها سوق صغير ور أيت في احد دكاكينها

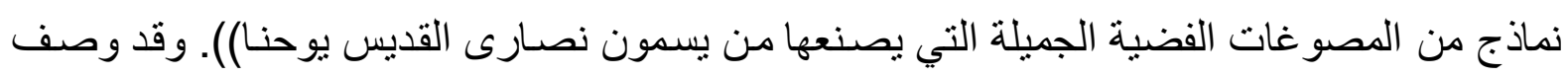

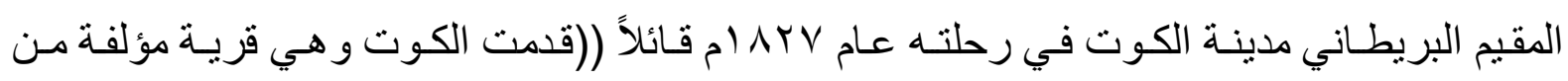


مجمو عة اكو اخ مبنية من القصب يحيط بها سور من طين ارتفاعه (T) اقدام وقال احد الرحالة الذين زاروا الكوت : ((كانت البلدة تتكون من الدور التي تفصل بينها ازقة وشوارع ضيقة ملتويـة ويقع في شمالها السراي المو اجه للنهر وفي شرقيه جامع كبير ثم يليه الاسواق وكانت في البلدة جامع كبير آخر مما يلي منطقة الاسو اق و حمام مطل على النهر وسوق مسقوف يسمى سوق الباثـا نسبة الى (محه باثـا الاغستاني).

وقال الرحالة (مكنن) في رحلته من البصرة الى بغداد ((وباز اء القرية (اي الكوت) جدول اسمه

شط الحي ومـن هنـا الى فوهـة نهر بسـى نهر العهـارة)). فيما قـال الاسـتاذ (عبد الرزاق الحسني) :

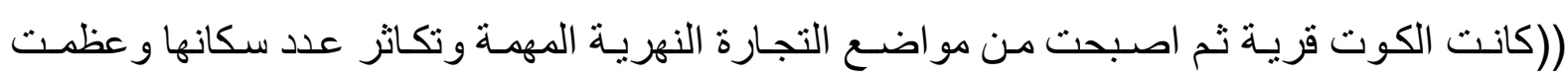
الهيتها و هي قبالة فم الغر اف الذي يصل دجلة بالغر اف ، تحبط بها المبـاه من ثلاثنة اطر افها وفيها جامعان وسوق مستطيلة واسواق اخرى متذاخلة، كما ان فيها جادة مستقيمة تحاد النهر واهاليها الى الى جانب كبير من الوداعـة وتقابـل قصبة الكوت على ضفة النهر اليمنى قريـة جسيمة يقال لهذه القريـة (صوب المكينة) و المقصود بها الفيصلية العزة حالياً.

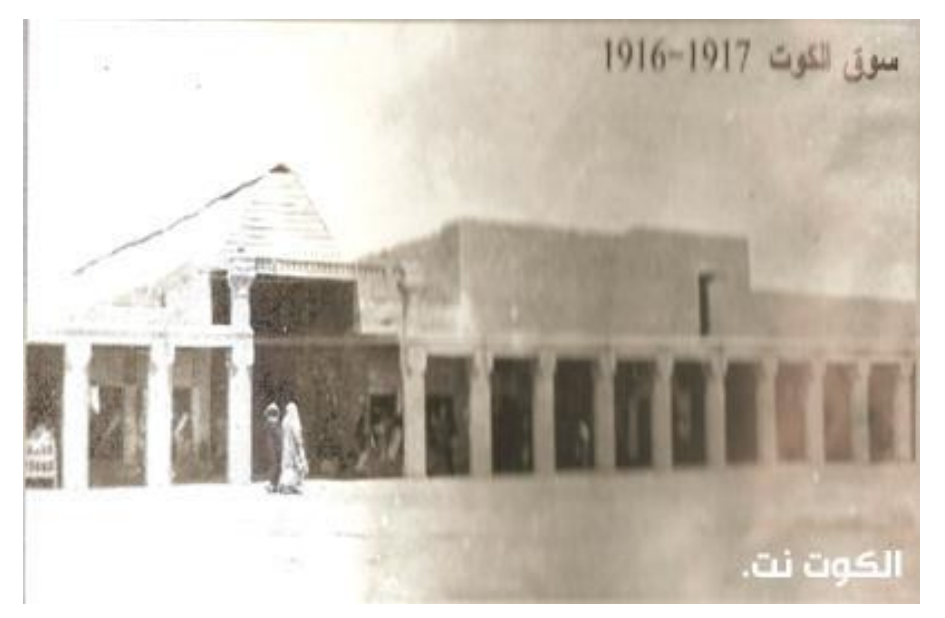

\section{حصار الكوت}

المعلومات التي سوف اتحدث بها عن حصسار الكوت مستمدة من كتابي (عالمية مدينة الكوت قصة الحصار) وكنت اعمل على جمع معلومات تفصيلية لكي تكون نتائج هذا البحث اقرب الى الدقة و الصو اب. لقد توخيت الدقة في اير اد هذه المعلومات وان جميع ماورد عن حصسار الكوت قد استقيتها عمن يوثق بقوة ذاكرتهم وصدق احاديثهم اضافة الى العديد من المصسادر التاريخيـة والعسكرية وسوف استعرض و اتابع مسيرة الحملة البريطانية من الهند الى البحرين ثم البصرة مروراً بالقرنة و العمارة منوقفاً عند معارك السن في الكوت متقصياً مسيرة طاونزند خلف قوات نور الدين الذي ترك الكوت منوجهاً بقو اتـه الـى المدائن نـاقلاً صـورة الاشتباكات الضـارمة التي حدثت في سـلمان بـاك و الخسائر 
الكبيرة التي منيت بها القو ات البريطانية حيث اجاب قائد طائرة الاستكثـاف العائدة من المدائن الى الكوت عن الاسئلة التي وجهت اليه قائلاً : انا لا اعرف إلَا انني اعتقد بان كل شيء قد انتهى، لقد تلقينا لكمة ثقيلة ... و عندها عاد طاونزند بقو اته المتبقية من المدائن الى .. اللج فالزور فالقطنية فالعزيزية

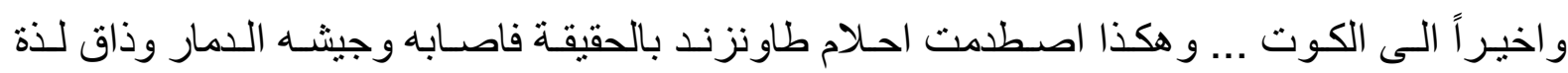
الانتصار السهل وتجرع مرارة الهزيمة ودخل الى الكوت يلعق جر احه و هزيمته جديدة من نوع آخر. بعد بـ إيوماً من الحصار تنتظرة.

كان طاونزند ينظر الى اهل الكوت نظرة شك واحتقار وكان اهل الكوت ينظرون البه ايضـاً نظرة حقد وازدراء ولم يرُق لهم ذلك الرجل مطلقاً كما لم يرُق لهم منظر ضباطه وجنوده وكانو ا يبدون في عيون الاهالي قذرين بالر غم من ملابسهم النظيفة التي كانو ا يرتدونها. لقد سطا الانكليز الغز اة على كل مـا ادخره اهل المدينـة من اطعمة فتركو هم يتضورون جو عاً طيلة ايام الحصار، بل ان الكثير من اهل المدينة ولاسيما الاطفال و المرضى ماتو امن الجوع. لقد كـان اهل الكوت ضـحية حصـارين. حصـار الاتر الك للمدينـة وحصـار الانكليز للاهـالي، وسنتحدث عن ماعاناه اهل البلد في فترة الحصار حتى تسليم طانزند المدينة الى التر الك دون اي قيد او شرطو هو الذي قال ساقاتل من بيت الى بيت و اجعل من الكوت بلاونا ثانية . الكوت هو الاسم الذي اذل طاونزنــ وقهره، وهذه البلدة الصـغيرة التي لمـع اسمهاو وتداولتها وكالات الانبـاء العالميـة واتجهـت اليـه الانظـار في جميـع انحساء العـالم تبحـث عنهـا على الخارطـة ، ولاعجب في ذلك فقد كان الحصار حدثاً ناريخياً هاماً لا بو ازيه إلا حصار بلادنا. يعتبر حصار الكوت اكبر فاجعة مذلة وقعت لأية حملة بريطانيا وكتب لهذا الحصسار ان يبقى بصبغته اكبر هزيمة شدتها بريطانيا بعد حصار دام V I ايوماً اضطر فيه سا الف عسكري بريطاني و هندي الاستسلام للقو ات التركية دون قيد او شرط ولم يقف الامر عند هذا الحد فمن بين با الف أسير حرب الذين استسلموا في الكوت لقي V آلاف اسير منهم حتفه فيما قتل سب الف آخرون في محاولات فاثلة كان الهدف منها فل الحصار عن القوات البريطانية.

عندما اعلنت روسيا الحرب على الدولة العثمانية حذت حذو ها كل من بريطانيا وفرنسا وتذرع الانكليز بحماية حقول النفط الاير انية وكما تذرعوا بحماية اصدقائهم امر اء الكويت ونجد. كما استعدوا ايضاً للاستيلاء على المنطقة من ايران الى البحر الابيض و البحر الاحمر وصولاً الى مصر لغرض وله السيطرة البحرية وتامين الطريق البري والبحري من بلادهم الى الهند. وكانو ا قد عزمو ا على احتلال العر اق الذي اكتشف فيه نفط كركوك عام 190 (م ، لذلك كله قررت الحكومة البريطانية تكليف حكومـة 
الهند بتنفيذ الحملة على العر اق فخصصت حكومة الهند لو اء المشـاة (7 ا ) من الفرقة السادسـة لاحتلال مصب شط العرب وسميت هذه القوة بالقوة (د) نسبة الى آمر اللو اء العميد ديلامين.

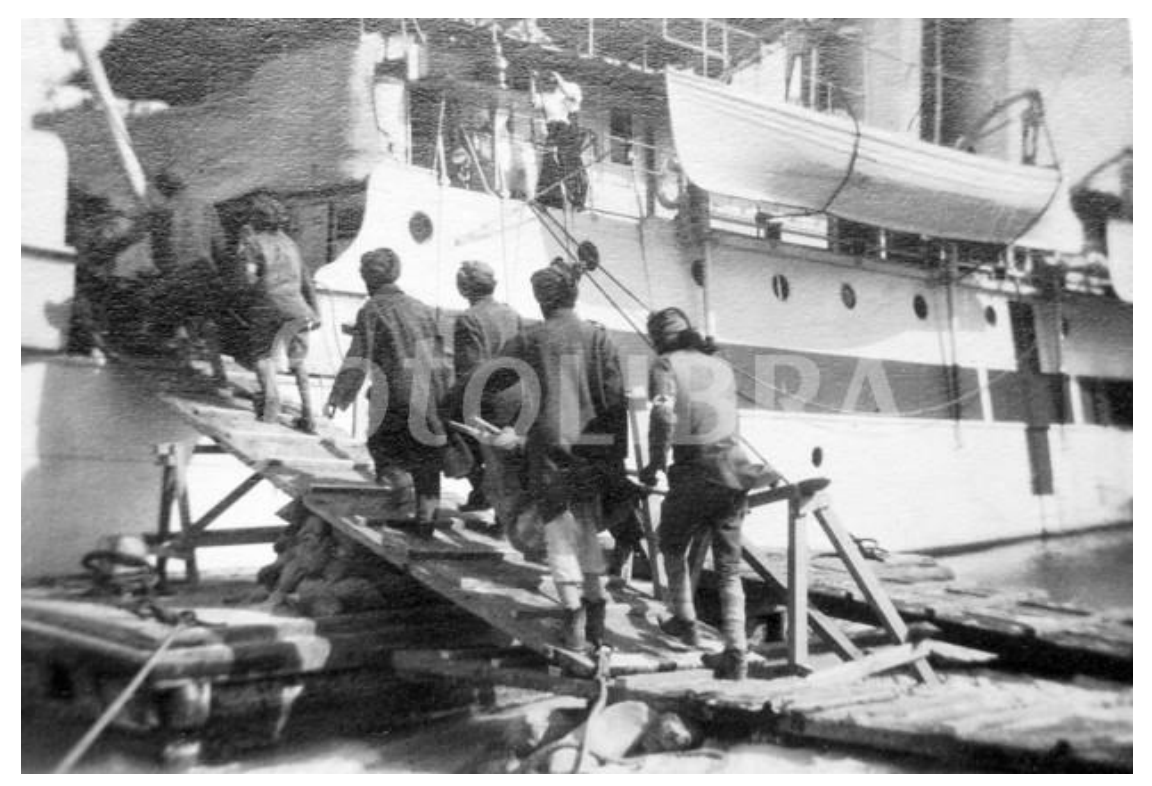

ابحرت القوه من ميناء بومباي الى البحرين ثم تقدمت من البحرين الى مصب شط العرب وفي صباح يوم (آ/تشرين الثاني/ء (و (م) استولت القوة على حصن الفاو دون مقاومسة فحطمت المدافع الاربعة والقت بها في شط العرب وانزلت قوة صغيرة في موقع السنية وقطعت سلك الهاتف الممتد بين البصرة والفـاو فنقطع الاتصـال الهاتفي بـين القيادة العثمانيـة وحاميـة الفـاو. شـرعت القوات الانليزيـة بالنزول و اكملت انز الها، فعلمت القيادة العثمانية بالاحتلال الانكليزي لموقع الفاو في وقت متاخر بسبب انقطاع اسلاك الهاتف ورداءة المو اصلات.

امر قائد الفرقة (^^) العثمانية بناليف قوة للدفاع عن البصرة ونتيجه لخسـائر القوات العثمانية في معركة السنية ومعركة سيحان ومعركة كوت الزين، قررت الانسحاب من البصرة ليلة (9 ( - ب. /تترين الثاني/ء (و (م) بدون قتال باتجاه القرنة . علم القائد البريطاني بانسحاب القوات العثمانيـة من البصرة فلخل بقو اته وسيطر على المدينة ومر افقها المهمة يوم (ب//تشرين الثاني/ع (9 ( ) وفي اليوم التالي (بr/تشرين الثاني/ء (9 () ) رفع العلم البريطاني على دار الحكومـة ، اي ان القوات البريطانية وصلت البصرة بعد سبعة عشر يوماً من الثروع بالحركات.

افلح الانكليز باحتلال البصرة وطمعوا بالتقدم شمالاً حتى جعلو ا من بغداد هدفاً لهم وبهذا فقد حققت الحملـة الانكليزيـة الغرض منهـا لانها ضمنت لبريطانيـا امـن منابع النفط ونتيجـة الانتصـار ات السهلة قررت التقدم نحو القرنة وسـارت بـاخرتين باتجاه القرنة و اطلقت نبران مدافعها على المواضع العثمانية في القرنة فأثر القصف على معنويـات الجنود فانسحب فوج درك نحو العمارة. وقرر (جاويد 
بك) القائد العثماني الانسحاب و هكذا سبطر الانكليز على هذا الموقع واصبحو ا يتحكمون بملتقى دجلة و الفرات بدون مقاومة تذكر.

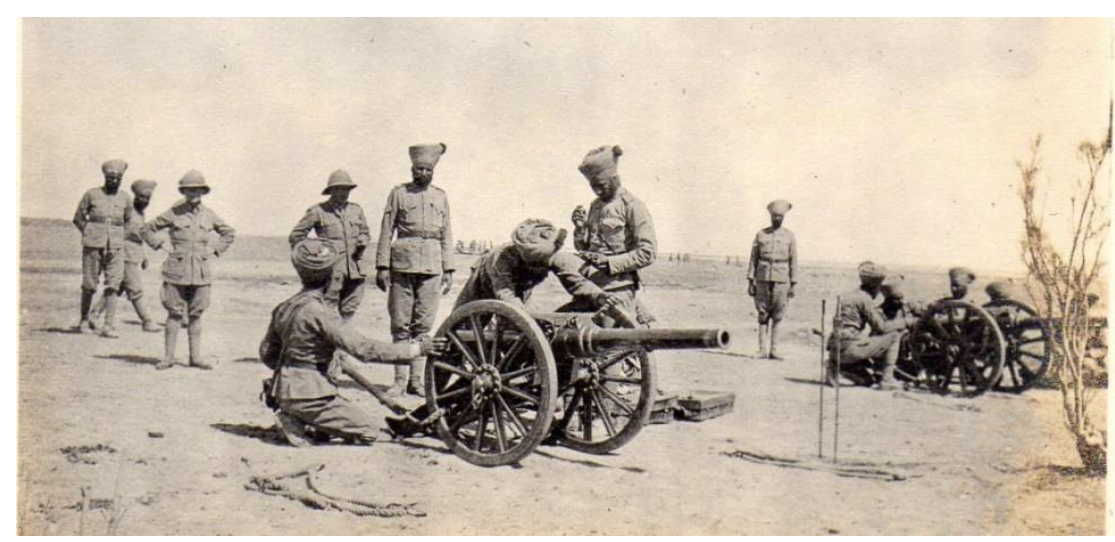

اشتذت مطامع الانكليز في العر اق بعد استسلام حامية القرنة. كلف اللواء طاونزند الذي وصل من الهند يوم (ب / نيسـان/ه (9 (م) قائداً لفرقة المشـاة السادسة بمهمة احتلال العمارة. كان من رأي قائد الفرقة العميد حليم بـل الانسـاب الـى العمـارة إلا ان القائد العام وافق على الانسحاب الى قلعة صـالح. علم طاونزند من الطائرة نبأ انسحاب العثمانيين ووصدل في مطاردته للقوات التركية الى قلعة صسالح وصعد شيخ المنطقة الى الباخرة فأمر طاونزند بان يجمع طعاماً لخمسة عشر الف جندي الذي قال عنهم بانهم سياتون في اعقابه لانه شعر بان الثيخ لن يدخر وقتاً في توصية الاتر الك وابلاغهم الخبر وبذلك انطلت الحيلة، وبينما كانت الباخرة تقترب من العمارة شوهد المئات من الجنود الاتر الك يتدفقون لعبور جسر مما جعل الباخرة تفتح النير ان عليهم بينما كانت بـاخرة اخرى ترسو عند دائرة الكمارك و على الفور صعد حاكم العمارة برفقة آر الحامية واستسلموا، و هكذا سقطت العمارة بسبب قيادة حليم بك الو اهنة.

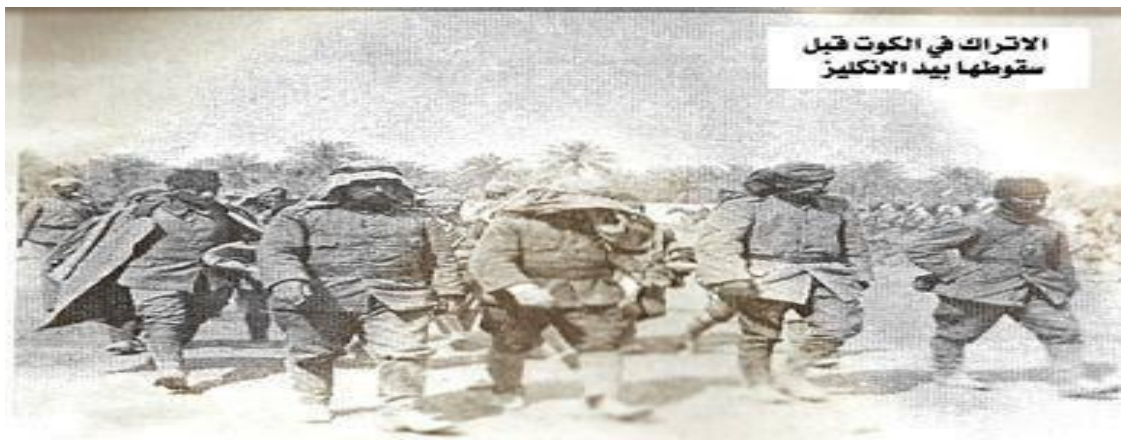

اتجهت القوات البريطانية نحو الكوت وكانت قوة نور الدين متخندقة على جانبي دجلة عند السن على بضعة اميال جنوب الكوت. بدأت الفرقة السادسة زحفها متبعين خط هاتف بصرة بغداد و عند السن بدأ القتال عنيفاً فاخبرت الطائر ات ان القوات العثمانية انسحبت خلسـة، لقد هزم نور الدين وصدر الامر لديلامين باحتلال الكوت يوم (9//ايلول/0 19 (م). عند احتلال الكوت شعر الانكليز بـان لديهم جيشـاً 
فنشلت خطة طاونزند الر امية الى تدمير قوة نور الدين لعدة اسباب فذخل طاونزند العزيزيـة في القت الذي وصلت قوات نـور الدين الى المدائن. كانت سـهولة الانتصـار ات التي حققها طاونزند في البصرة و القرنة و العمارة و الكوت شجعه على التقام نحو المدائن كما وصلت رسالة من مجلس الوزر اء البريطاني بانه اذا كان بالامكان احتلال بغداد و الاحتفاظ بها، فان هناك اسباب سياسية تؤيد ذلك لان بغداد لها اسم تاريخي رنان في العالم كما ان احتلال بغداد يعوضـهم عن الانتكاسـات التي اصـابتهم في معارك الدردنيل.

\section{جعل طاونرند هن العزيرية نقطة للزحف نهو بغداد.}

شرعت القوات البريطانية بالتقدم وامام تحصينات القوات التركية في المدائن، شرعت الفرقة السادسة بكاملها بالهجوم.

معركة سلمان باك : اندفعت قوات طاونزند نحو سلمان بـاك و هنالك حدثت اعظم معارك الحرب مـن حيث اهمية نتائجها، فكانت اول معركةوقف الجيش التركي فيها موقف الند للند تجاه الجيش الانكليزي وصار عه فغلبه و اخذ يكيل لله الضربات القاصمة. يقول طاونزند في مذكر اته عن معارك سلمان باك انني رجعت بعد المعركة الدامية التي تشيب لها رؤوس الاطفال وتر اجعت ، 9 ميلا ومقدمة الجيش التركي تجر في اثري. امـا القائد التركي فيقول (كان القتـال مذبحة رهيبة، حيـث اثـتبك فيها جنـود

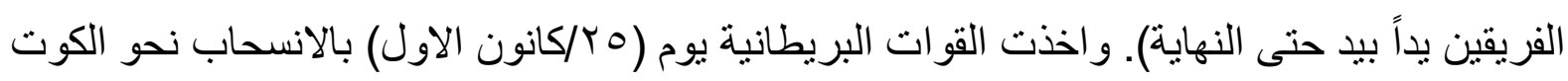
مسـتفيدة مـن ظـلام الليـل. و بعـد ان تلاحمـو اللقتـال كـان هنـاك سـيل مـن الجرحىى وسـيل مـن الجنـود البريطانيين و الهنود بلا قيادة. كانوا جميعاً منهكي القوى عطثى جياع، وابلغ هوتن طونزند بان الوضع على جناحه الايسر ميؤساً منه. اجاب طاونزند بانه ميؤس منه في كل مكان ومن بين . . 10 مقاتل فقد طاونزند اربعة آلاف منهم.

وبغداد التي كانت بالامس حلماً اصبحت و هماً. اصبح على طاونزند العمل على انقاذ مـا تبقى

من فرقته والتقهقر بهل الـى اللج فالزور فالقطنيـة فالعزيزيـة واخيراً الكوت. بعد ان ابلـغ نور الدين بانسحاب طاونزند بدأ بمطاردة قواته. لقد نفذت فرقته تقهقر اً دام ستة ايام. لقد كان واجب طاونزند قيادة قو اتـه الـى بـر الامـان، والامـان بالنسبة لـه يعنـي الكوت. خـرج العميد رومنغتون آمـر حاميـة الكوت لاستقبال طاونزند فعرض عليه رأيه الخاص باحتلال الخنادق التركية القديمة في السن. وفي (r/كانون الاول/0 19 (م) وصلت قوات طاونزند الكوت وشرعت بتحصين دفاعاتها مستفيدة من عطفة نهر دجلة لان الكوت محاطة من جو انبها الثلاثتة بنهر دجلة، وان نهر اً واسعاً من ثنلاث جو انب لايقل اهيبة في الجانب العسكري عن ثثلاثة جدران عاليـة امـا الجزء الرابع من الكوت وهو الجوء المفتوح فقد كان بالامكان تحصينه وقد عرض آمر قو ات الكوت عليه رأياً بان يكون توقف قطعاتـه في موضـع السن إلاً 
ان طاونزند رفض ذلك وقد اثبتت الايام بُعد نظر هذا القائد وصحة رأيه. وما ان نهض الجنود من النوم حتى طلب منهم ان يقوموا بحفر الخنادق. لقد امر بحفر r خطوط من الخنادق و عثر ات من خطوط الالغام و المخابي ومو اقع المدفعية وصفوف من الاسلاك الثـائكة. كما امر بمد اسلاك البرق من قيادته في المدينة الى مقرات الالوية الاربعة.

طلب طاونزند من قيادته باخلاء المدينة إلًا ان قيادته رفضت ذلك بتوجيه سير (برسي كوكس) حذره من مغبة هذا الاجر اء قائلاً : ان النساء والاطفال سيهلكون في الصحر اءو وان ذلك سيُحدث تاثيراً دعائياً سيئًا. وقد و افق طاونزند على ذلك رغم انـه يكره اهل الكوت ويعتبر هم خونه وهو يقول في هي مذكر اته (قد اسفت اثد الاسف لتساهلي لانني لا اهتم قلامة ظفر بمن بقتل او يموت في الصحر اء من هؤلاء العرب الخائنين لانهم لم يستحقو ا درة من الرحمة و الثفقة). ان عدم اخلاء المدينة لم يكن العطف على النسـاء والاطفال و انما الحفاظ على سمعة بريطانيا

$$
\text { لكي لاتلام على ذلك في طول العالم الاسلامي وعرضه. }
$$

ا ـ احال طاونزند ب ا رجلاً من اهالي الكوت لمحكمة الميدان التي اعدمه فوراً رمياً بالرصاص. r- أمر طاونزند باستخدام سكان البلدة في حفر خنادق الجنود و انشاء الطرق. ب- هدم الانكليز عشر ات البيوت لفتح ازقة واسعة تكفي لعبور عربات النقل. ع - تم الاستيلاء على سوق البلدة وطردوا اصحاب الدكاكين. حيث حولو السوق الى مستشفى وفقل اليه مئات المرضى و الجرحى.

ــ قام الجنـود الانكليز بـالتحري عن الحبـوب المتيسرة للدى الاهـالي ومصسادرتها، وصساروا يفتشـون البيوت ويهدمون جدر انها وسقوفها بحثناً عن الحبوب التي بدخر ها الاهلون، وهذا التفتيش يجري بشكل مستمر. 7- عاش اهل الكوت مشقة كبرى في الحصول على الماء لان الاتر الك يطلقون النار على كل من يقترب من النهر. V- عانى اهل الكوت من شحة الوقود فقد دأب الجنود على انتهاب كل الاخشـاب التي وجدو ها في البلدة و اقتلعو ا شبابيك البيوت و ابو ابها، فكان اصعب الامور على الاهالي اعداد الخبز وطبخ الطعام. ^ـ نتيجة القصف الذي كان ينهال على المدينة من كل زاوية، قطعت رؤوس الاشجار و النخيل. 
9 ـ كانت المدافع التركية تقصف المدينة بمعدل يزيد على الف قذيفة مدفع يومياً اضافة لقصف الطائرات فكانت تؤدي الى نسف البيوت وقتل المو اطنين. • 1 - يوم المدينة قذائف تتفجر ، طائر ات تقصف ، رصاص يأز ، دخان يتصاعد. مر احل الحصار :تقسم ايام الحصار الة ثلاثنة مر احل: المرحلة الاولى : التي تبدأ من اليوم الاول للحصسار ، و هي \/كانون الاول/ه ا9 (م ـ وفيها

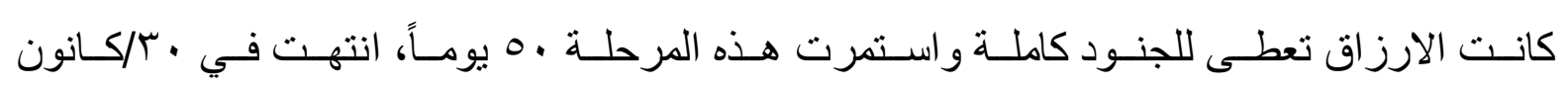

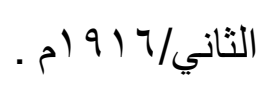

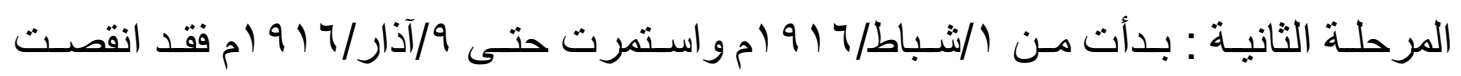

$$
\text { الارزاق الى النصف. }
$$

المرحلة الثالثة : و هي المرحلة الاخيرة والتي كانت الارزاق فيها تكاد لاتكفي إلآ لسد الرمق،

وقد استمرت هذه المرحلة . م يوماً. شرع الجنود ياكلون الكلاب والقطط حتى نفذت تماما ولم ينجو إلَا كلب طاونزند وكلبي الجنر ال مليس.

مستشفيات المدينة اثناء الحصار : عندما نستعرض الوضع في مستشفيات المدينة لم يكن قصدنا معرفة حالة جنود الحملة فهم بين جريح ومريض ولكننا نريد التوصل الى نتيجة مهمة وهي : اذا كان هذا حال جنود الامبر اطورية البريطانية فما هي حال اهالي الكوت رعايا الدولة العثمانية. فما يسمى مستشفيات، هي اماكن قذرة وخدمات طبية محزنة، الرجال ممددين و هم يسبحون في برك من الدم والبول و الغائط اجسامهم لزجـة بـالبراز جر احهم مليئة باليرقات ، عظـامهم المهشمة مجبرة بخثـب صناديق الويسكي وقبضات المعاول. و العمليات كانت تجرى على طاولة خشبية على ضوء الفو انيس النفطية تحت هدير القنابل ليلاً ونهار اً، مايسمى مستشفيات اماكن قذرة وخدمات طبية مخزية.

خفض استحقاق الجنود من الطعام : يعطى رغيف و احد كل يوم ولتر واحد من الماء. انقصت كمبة

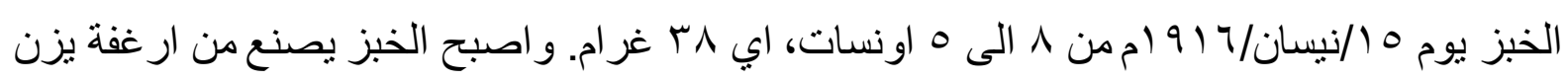
الو احد منها ـ ا اونسات، فيتقاسم كل اثنين واحداً من تلك الارغفة .. ترى كيف يستطيع القائد ان يقسم هذا الرغيف بحيث يثيب كل فرد ه اونسات، لقد نوصلت الى: ان يقوم احد الرجلين بقطع الرغيف الى لى

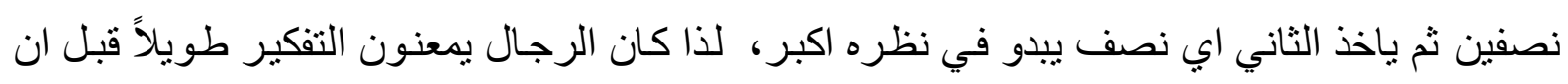
يثر عون بقطعه بالدقة والتركيز وكانهم يجرون عملية جر احية على دماغ بشر ، حينئذ يحدق الثاني ويكسب الوقت قبل ان يختار. 
السجائر في الحصار : كانت السجائر مصدر قلق آخر ... فالرجال يصبرون بدون طعام وتسلية ولكن

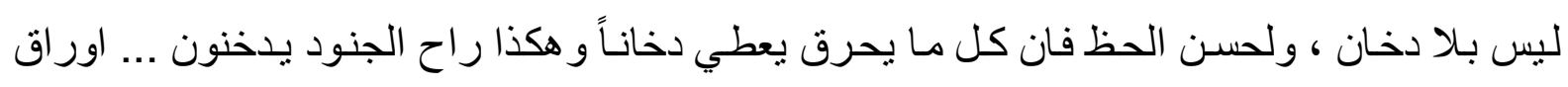
الثاي المستعملة وجذور الحطب ... واور اق اشجار الليمون التي كانو ا يسمونها سخرية (فرجينيا معدل الطابوق). و بعد ان يدخنو ا هذا النوع الذي يسمى مجاز اً سجارة يسعلون كالمسلولين ثم يستسلمو الحياة

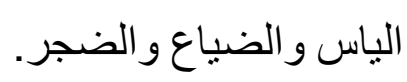

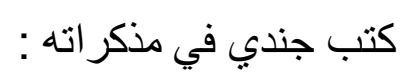

ـ اطلق النار على عربي فسقط ولكنه نهض و هو يمسك صدره ثم طلب جندي من العريف ان يأذن لله بمحاولة اخرى فاجاب : لا دعه يهرب فتللك كافية له (جرى هذا لمجرد التسلية). ـ كتب جندي آخر في مذكر اتـه : ان احد الاعر اب جاء الى ضفة النهر لبيع بضـاعة فاخترت منها مـا احتجت اليه وبانا نساومه بختّونة فقام شوتر و ادوارد بنهب بضـاعته و هربـا امـا انـا فدفعته الى اسفل الجرف فتدحرج.

ـ كتب طاونزند في مذكر اته : انه لاياخذ اهالي الكوت النقود الورقية في البيع من الجنود لانهم يعتقدون بفوز الاتر الك عليناورلا استطيع ان اجلد 7 الاف نسمة. ـ كتب ضـابط في مذكر اتهـ ان اهـل الكوت يبدو عليهم الهز ال و الكآبـة بشكل مر عب وكانوا يموتون بالمئات. ـ غدت الافخاذ نحيفة جداً و اصبحت الاصسابع بارزة العظام وبدت الاسنان كبيرة وصارت العيون غائرة. ـ اصبح النعاس الناثـيء عن الجوع الحاد من الامور الواضحة، فكان كل و احد من الحرس في الايسام الاخيرة بيقط نائما سو اء كان و اقفاً او قاعداً وتبلدت الاحاسيس.

ـ اصبحت الملابس رثثة وتشـخة بشكل لايمكن وصفه، فلقد كان البعض يقول آه لو استطيع ان اغير قميصي ولكن الجو اب الذي يتلقاه هو : ان الثيء الذي تستطيع تغبيره هو قملك. ـ مطاعم الضباط نفذ منها السكر والملح وظل لحم الخيل يقدم خالٍ من الملح فيترك مذاقه في الفم وكانـه مادة معدنية.

ـ قام عريف بقص شعر احد الجنود بمقص لقص بردعة البغال ... كان الامر مقو لا تماما. - يقول الجنود كان لحم الخيل طيباً في حين كان لحم البغال شديد العصب امـا لحم الثيران فكان يحطم الفكوك. - طالب الضباط تجاوز الرتابة في الطعام الذي يقدم لهم فتقرر اضافة لسان البغل. 
ـ صار الجميع يبحثون عن الحشـائش لبطبخو ا منـه طعامـا لـه شهية ظـاهري بالسبانغ فيتحول الى مـادة خضر اء اللون سوداء ، وقد كانـت الحشـائش في بعض الاحيـان تحتوي على انو اع سـامة وقد مـات الجنر ال هوتن من اكلة سبانغ فيها نوع من الحشـائش السـامة فصدر الامر التالي للحاميـة (التوقف عن بعن اهن

(كل الحشيش)

- راح الرجال يتعقبون ويمسكون كل شيء يتحرك على الارض فياكلونه بعد قليه بزيت المحركات. - شرقت كل اريكة من كل مقهى و احرقت. - حين بدات الليالي تبرد اكثر راحت الصلبان الخثبية تسرق من المقبرة لاستعمالها كحطب. ـ لم يبق وتد واحد ـ لقد قلعت كلهاو استعملت وقوداً وصدر القرار التالي (من يلق عليه القبض متلبسـاً بجريمة سرقة وتد سوف ينفذ فيه حكم الاعدام). ـ كانت النار الخاصة ممنو عة سال الجندي اذاً كيف ناكله قال العريف اي شيء هو قال الجندي الكلب العجوز الذي ذبحناه قال جندي آخر : جيفة طيبة المذاق. محاولات فلك الحصار: كان ايلمر قائداً للقوة التي افلحت في فلك الحصسار عن قوة طاونزند عندما كان محاصر اً في جتر ال سنة 190 (م عندما كان طاونزند نقيباً، واتيحت لآيلمر فرصة جديدة مشـابهة ، وصل ايلمر الى العراق وتولى قيادة فيلق دجلة المكلف بانقاذ قوة طاونزند المحاصرة، حشد ايلمر قوته في علي الغربي فقرر العمبد نور الدين التصدي لقواته التي تحاول فلك الحصسار عن الكوت وحدثت بات

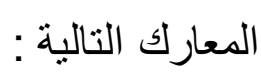

$$
\text { r }
$$

ع - معركة سابس ، وقد رفع القائد التركي علي احسان شعارًا (من يحب الله فليذهب الى سابس) - - ـ - معركة الفلاحية الثالثة

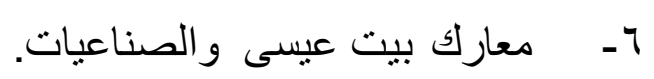

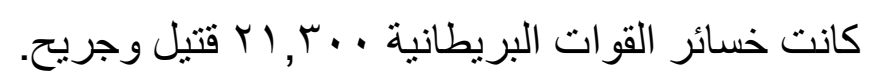

بعد فنشل كل هذه المحاو لات جرى القاء بعض المو اد الضرورية من الطائر ات الخفيفة . فالقت رحى طاحونـة تعويضـا عن الرحى التالفة وشباط صبد ورسـائل سقطت كلها في نهر دجلة. وجرت محاولة لاعاثة القوة جواً فسقط قسم من الطعام في نهر دجلة وسقط القسم الاخر على القو ات التركية. 
آخر المحاو لات الباخرة جلنار. حاول الانكليز ارسال سفينة محملة بمئات الاطنان من مواد الاعاثة الى الكوت فتقرر ارسـال المواد على ظهر الباخرة جلنـار وكانت اسـرع بـاخرة للنقل وقد ارتاى الانكليز شحنها وارسـالها الى الكوت وقد در عها الانكليز لوقايتها من الرصساص ثم شحنو ها بـ · rV طناً مـن المو اد الغذائية استطاع الاتر الك ان يعلمو ا بخبر ها فلما وصلت الكوت شعر بها حر اس الثاطيء و اطلقو المال عليها النار بكثافة فقتلو ا عدداً من نوتيتها وجرحو ا اخرين فما لبثت السفينة ان اصطدمت بحبل سلكي كان العثمـنيون قد مدوه عبر نهر دجلة فاتجهت منحرفة نحو اتجـاه ذلك السلك حتى استقرت على الثاطيء قرب عبارة المقاصيص، عندئذ انهال عليها الجنود فافرغوا القسم الاكبر من الارزاق المحملة فيها فلما علم طاونزند وجنوده بمصير جلنار اصيبو ا بخيبة امل كبيرة.

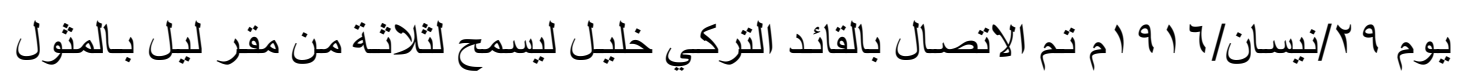
امامه. قابل خليل الوفد بعد طول انتظار عرضوا عليه مبلغ الفدية الجديد مليوني باوند ذهب وان : 1 - يتعهد بان يحارب افر اد حامية الكوت الاتر الك طيلة الحرب

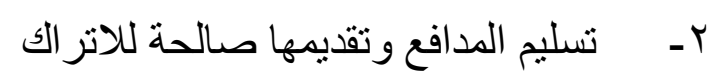

جاء رد وزير الدفاع انو باثـا بـان تسليم حامية الكوت دون قيد او شرط فتقرر استسـلام الحاميـة في م) $917 /$ T 9

ا - سمح طاونزند لجنوده وضباطه بتناول ارزاق الطو اريء التب بحوزتهم طول فترة الحصار. r - قام ضابط بطمر مسدساتهم وتحطيم سيوفهم. rـ قام الجنود بتدمير بنادقهم ورشاشاتهم ولم يحتفظوا بسوى بندقية واحدة في كل سرية لحماية انفسهر. ع ـ قام الجنود بتمزيق خيامهح و افرشتهم. ــ القيت في النهر النواظير و اسلاك المخابرة.

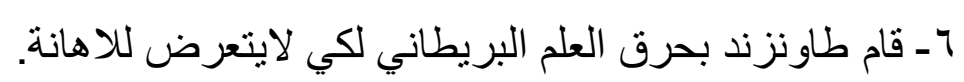
V- فام جنود الحامية باتلاف سء مدفع. 1ـ اتلف الضباط الاور اق الرسمية والخر ائط واور اق الجفرة.

9 ـ كان اخر ما دمر جهاز اللاسلكي بعد ان بث رسالة طاونزند الوداعية الى قيادة البصرة قال فيها : لقد رفعت الر اية البيضاء فوق الكوت ، " لسوف احطم جهازنا اللاسلكي انه لبسرنا بـان يعرف

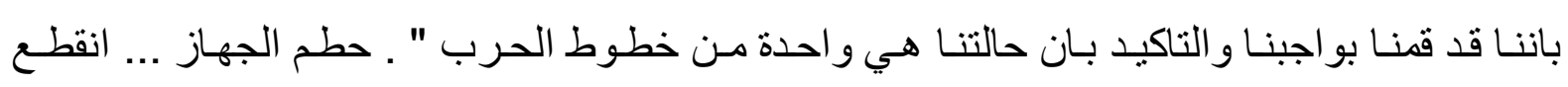
الاتصال ... بدأ الاستسلام. بولاهل 
عندما قدم اللو اء طاونزند سيفه ومسدسه للقائد العثماني خليل باثنا اعادهما الاخير اليهه من بـاب المجاملة لاسيره. في آخر الامر طلب طاونزند من خليل باثنا ان يبعث بكلبه سيوت الى البصرة و امن خليل باشا بوقار على ذلك الطلب لان الاسر للرجال وليس للكلاب. هكذا انقذ طاونزند كلبه وضيع جنده.

الاستسلام : بعد الظهر بقليل ارتفعت الاعلام البيضـاء على خطوط الانكليز في الكوت ... فدخل فوج تركي البلدة يقوده عقيد ، هو نظمي بك ، كان بمتطي صـهوة جو اده والجند يسبرون خلفه على نغمات الطبول، ما ان رفع العلم العثماني حتى تم الاستيلاء بسر عة فائقة على المخازن و البيوت ومقر طاونزند وخر ج رجال الفرقة السادسة البريطانية المحاصرة من خنادقهم و لاول مرة خلال مئة وثلاثة و اربعين يوماً يقفون منتصبين ور احت جماعات من الرجال تتجول دون هدف وهي تقصدان تستمتع بالهو اء الطلق و اشعة الثمس والامن ولم يعر ما يشوه جمال هذا الصباح سوى رائحة جثث القتلى. وعلى الرغم من المصيبة التي حلت بهذه المدينة خلال مدة حصـار ها فان الاتر الك سر عان مـا بدات حملات الاعدام بوم · ب/نيسان/7 ا (9 ام ـ وكانت تجري على شكل وجبات بدات الوجبة الاولى:

$$
\text { ا - الحاج عباس العلي وولديه سعد و علي }
$$

r

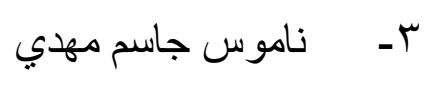

ع - باسين الجعيفري

0- خماس جبارة الطائي

7- حسوني رطيبة الملطاثي

V- عباس ظاهر جميعي الجميلي وكان مختار ا اعدم لوحده وقت الضحى

A- - ملي عبود سليمان السيفاوي

9 - داود عبود سليمان السيفاوي

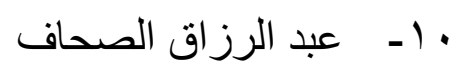

$$
\text { 11 - - كاظم عيسى موسى }
$$

وصل مجموع من اعدام ، . ش شخصاً

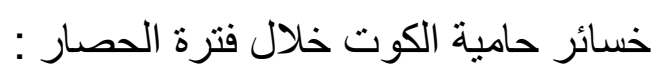

ـ إ إنتيل ومنوفي

11/ أ جريح ومريض

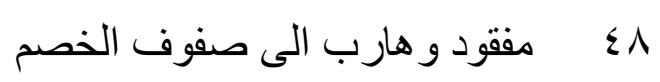




$$
\begin{aligned}
& \text { عدد الاسرى الذين استسلموا في الكوت } \\
& \text { rqV. }
\end{aligned}
$$

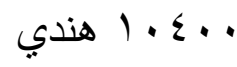

$$
\begin{aligned}
& \text { • }
\end{aligned}
$$

فقدت قو ات الانقاذ نتيجة للهجمات المتعاقبة ه هrr, إع مقاتلاً

الجنـر ال سـير سـتانلي مـود: عينـت القيـادة الانكليزيـة سـير سـتانلي مـود قائداً للحملـة على العـراق في 1//آب/ آ آ أم وقد رات وزارة الحرب البريطانية اعادة النظر في واجبات الحملة بعد استسلام حامية الكوت فجعلتها محصورة بالمهمات التالية :

$$
\text { r }
$$

|لإسادر

ا - طاونزند ـ تشارلي : محاربتي في العراق ـ ترجمة عبد المسيح وزير.

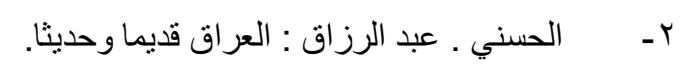

r - الورد ـ ـ حامد : السوقية البريطانية في العراق.

ع - هيكل حمد حسنين : حرب الخليج.

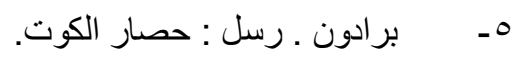

7- - لونكريك .س ـ هـ : اربعة قرون منتاريخ العراق الحديث ـ ترجمة جعفر خياط.

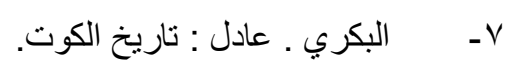

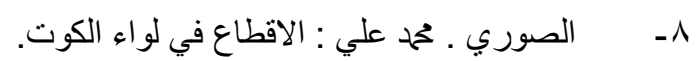

9- العزاوي . عباس : تاريخ العراق بين احتلالين.

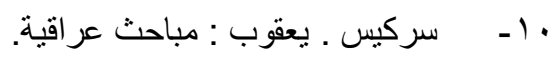

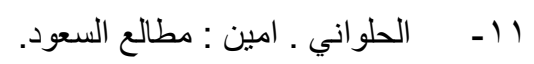

r ا - الصديقي ـ مصطفى : كثف الصدى و غسل الران في زيارة العر اق وما والاها من البلدان.

سا -

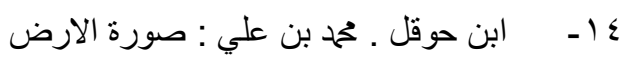

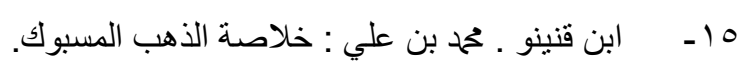

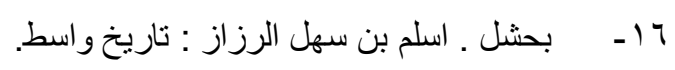

